\title{
Risk factor control and outpatient attendance in young adults with diabetes
}

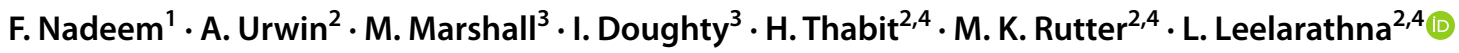

Received: 30 September 2018 / Accepted: 16 November 2018 / Published online: 21 December 2018

(c) The Author(s) 2018

Keywords Type 1 diabetes · Type 2 diabetes $\cdot$ Young adults $\cdot$ Transition

$\begin{array}{ll}\text { Abbreviations } \\ \text { BMI } & \text { Body mass index } \\ \text { BP } & \text { Blood pressure } \\ \text { HDL } & \text { High-density lipoprotein } \\ \text { IMD } & \text { Index of Multiple Deprivation } 2015 \\ \text { LDL } & \text { Low-density lipoprotein } \\ \text { T1DM } & \text { Type 1 diabetes } \\ \text { T2DM } & \text { Type 2 diabetes } \\ \text { TC } & \text { Total cholesterol }\end{array}$

\section{Introduction}

Diabetes is one of the commonest chronic medical conditions amongst those aged 18-25 years. Type 1 diabetes (T1DM) predominates in this age group, but, recently, the prevalence of type 2 diabetes (T2DM) has also increased in young adults. Young people experience various social, psychological, and physiological changes, often leading to poor glycaemic control and non-engagement with health services [1].

Managed by Massimo Porta.

L. Leelarathna

lalantha.leelarathna@cmft.nhs.uk

1 School of Medicine, Faculty of Biology, Medicine and Health, University of Manchester, Manchester, UK

2 Manchester Diabetes Centre, Manchester University NHS Foundation Trust, Manchester Academic Health Science Centre, Manchester, UK

3 Royal Manchester Children's Hospital, Manchester University NHS Foundation Trust, Manchester, UK

4 Division of Diabetes, Endocrinology and Gastroenterology, Faculty of Biology, Medicine and Health, University of Manchester, Manchester, UK
Improving glycaemic control and controlling cardiovascular risk factors may reduce long-term complications [2]. This is particularly relevant for those who develop diabetes at a younger age due to its life-long nature and potential metabolic memory imprinting on vascular complications. We undertook a retrospective service evaluation in a large tertiary diabetes centre to assess glycaemic control, cardiovascular risk, and outpatient attendance of 18-25 years old.

\section{Methods}

This was a retrospective, observational, single-centre, service evaluation in a tertiary referral centre in the North West of UK with approximately 1500 individuals with T1DM and 2000 individuals with T2DM. We included individuals aged 18-25 years who attended at least one medical appointment $(n=240)$.

As a service evaluation, no ethical approval was required. Data were collected from electronic records. HbA1c values were used from the most recent 12-month period at Manchester Diabetes Center. Data on weight, blood pressure (BP), and lipids were collected from the most recent visit. Non-attendance rates were calculated only after the exclusion of cancelled appointments. For each participant postcode, we obtained the English Index of Multiple Deprivation 2015 (IMD) from the Department for Communities and Local Government. The IMD is the official measure of relative deprivation for small areas in England, which ranks these areas from 1 (most deprived area) to 32,844 (least deprived area). We used IBM SPSS version 22 (IBM UK, Portsmouth) for statistical analysis. 


\section{Results}

Two hundred and forty individuals aged 18-25 years (at March 2016) attended Manchester Diabetes Centre between November 2007 and May 2016. Of these, follow-up data were available, HbA1c for 223 (93\%), lipids for 219 (91\%), BP for 223 (93\%), and BMI for 214 (89\%) individuals.

Baseline characteristics are shown in Table 1.

\section{Glycaemic control}

For the whole cohort, the median number of HbA1c tests performed during the most recent 12 -month period was 2 $(1,3)$. The median HbA1c level was $70(57,88) \mathrm{mmol} / \mathrm{mol}$ [8.6 $(7.4,10.2 \%)]$. Females tended towards poorer glycaemic control; $72(8.7 \%)$ vs. $68(8.4 \%) \mathrm{mmol} / \mathrm{mol}, p=0.052$. Only $19 \%$ of the group had an HbA1c level $\leq 53 \mathrm{mmol} /$

Table 1 Baseline characteristics

\begin{tabular}{ll}
\hline Characteristic & Data \\
\hline$N$ & 240 \\
Females & $121(50 \%)$ \\
Current age (year) & $23(21,24)$ \\
Age at diagnosis (year) & $12(7,16)$ \\
Duration of diabetes (year) & $11(5,15)$ \\
Type 1 diabetes & $209(87 \%)$ \\
Type 2 diabetes & $24(10 \%)$ \\
Continuous subcutaneous insulin infusion & $78(37 \%)^{\mathrm{a}}$ \\
$\quad$ CSII) & \\
IMD & $8200(3295,13,149)$ \\
\hline
\end{tabular}

Data are $N(\%)$ or median (IQR) unless stated

IMD english index of multiple deprivation 2015

${ }^{\text {a }}$ Type 1 diabetes only

Table 2 Levels of cardiovascular risk factors and the proportion of individuals achieving treatment targets for type 1 and type 2 diabetes mol (7\%). More than half of individuals (52\%) had an HbA1c level $>69 \mathrm{mmol} / \mathrm{mol}(8.5 \%)$ and $26 \%$ had an HbA1c $>86 \mathrm{mmol} / \mathrm{mol}(10 \%)$ indicating poor or very poor glycaemic control.

Individuals with T1DM had significantly higher HbA1c compared to T2DM, 72 (8.7\%) vs 49 (6.6\%) mmol/mol, $p<0.001$. Of those with T1DM, only $15 \%$ had an HbA1c level $\leq 53 \mathrm{mmol} / \mathrm{mol}$ (7\%), $22 \%$ had HbAlc level $\leq 59 \mathrm{mmol} /$ mol, and $56 \%$ with $\mathrm{HbA} 1 \mathrm{c} \geq 69 \mathrm{mmol} / \mathrm{mol}$. Of individuals with T1DM ( $n=209), 78(37 \%)$ were treated with insulin pump therapy. There was no difference in median HbA1c between pump users and injection users, [75 (9.0\%) vs. 70 $(8.6 \%) \mathrm{mmol} / \mathrm{mol}, p=0.15]$. Longer duration of diabetes $(r=0.3, p<0.001)$ was associated with higher HbA1c levels.

\section{Cardiovascular risk factor levels}

Table 2 shows the median levels of HbA1c, blood lipids, $\mathrm{BP}$, andbody mass index (BMI) separately for individuals with T1DM and T2DM separately. Less than one-third of the cohort with both types of diabetes had a total cholesterol (TC) $<4$ mmols. LDL-cholesterol levels were broadly comparable in T1DM and T2DM, while more individuals with T1DM achieved HDL cholesterol targets. Triglyceride levels were numerically higher in those with T2DM. In contrast, BP was well controlled in the majority. Of the total cohort, $35 \%$ were overweight (BMI: $25-30 \mathrm{~kg} / \mathrm{m}^{2}$ ) and $17 \%$ were obese $\left(\mathrm{BMI}>30 \mathrm{~kg} / \mathrm{m}^{2}\right)$. Only $47 \%$ had an ideal BMI between 18 and 25 (in $2 \%$ BMI was $<18 \mathrm{~kg} / \mathrm{m}^{2}$ ). For those with T1DM, $46 \%$ were overweight or obese (BMI $\geq 25 \mathrm{~kg}$ / $\mathrm{m}^{2}$ ). Taken as a whole, higher BMI was associated with higher LDL ( $r=0.16, p=0.026)$, lower high-density lipoprotein (HDL) $(r=0.26, p=<0.001)$, higher triglycerides ( $r=0.33, p<0.001)$, higher systolic $(r=0.36, p<0.001)$, and diastolic BP $(r=0.24, p<0.001)$.

\begin{tabular}{|c|c|c|c|c|c|c|c|}
\hline & \multirow[t]{2}{*}{ Treatment target } & \multicolumn{3}{|l|}{ Type 1 diabetes } & \multicolumn{3}{|l|}{ Type 2 diabetes } \\
\hline & & Median (IQR) & $N$ & $\begin{array}{l}\text { \% Achiev- } \\
\text { ing target }\end{array}$ & Median (IQR) & $N$ & $\begin{array}{l}\% \text { Achiev- } \\
\text { ing target }\end{array}$ \\
\hline $\mathrm{HbA1c}$ & $<=53 \mathrm{mmol} / \mathrm{mol}$ & $72(60,88)$ & 192 & 15 & $49(39,68)$ & 24 & 54 \\
\hline $\mathrm{TC}$ & $<4 \mathrm{mmol} / \mathrm{L}$ & $4.7(4.0,5.1)$ & 188 & 29 & $4.7(4.0,5.1)$ & 24 & 25 \\
\hline LDL-C & $<2 \mathrm{mmol} / \mathrm{L}$ & $2.4(1.9,2.9)$ & 181 & 30 & $2.5(1.7,3.1)$ & 22 & 32 \\
\hline HDL-C & $\geq 1$ or $1.2 \mathrm{mmol} / \mathrm{L}^{\mathrm{a}}$ & $1.6(1.3,1.9)$ & 188 & 90 & $1.0(0.9,1.1)$ & 24 & 45 \\
\hline Triglycerides & $\leq 1.7 \mathrm{mmol} / \mathrm{L}$ & $1.0(0.7,1.6)$ & 188 & 83 & $2.1(1.3,2.9)$ & 24 & 42 \\
\hline Systolic BP & $140 \mathrm{mmHg}$ & $124(119,132)$ & 197 & 95 & $126(123,130)$ & 20 & 90 \\
\hline Diastolic BP & $85 \mathrm{mmHg}$ & $70(63,75)$ & 197 & 99 & $73(67,80)$ & 20 & 90 \\
\hline BMI & $\geq 18$ to $<25 \mathrm{~kg} / \mathrm{m}^{2}$ & $24(22,27)$ & 187 & 54 & $30(26,33)$ & 22 & 13 \\
\hline
\end{tabular}

$T C$ total cholesterol, $L D L-C$ low-density lipoprotein cholesterol, $H D L-C$ high-density lipoprotein cholesterol, $B P$ blood pressure, $B M I$ body mass index $\left(\mathrm{kg} / \mathrm{m}^{2}\right)$

${ }^{\mathrm{a}} \geq 1 \mathrm{mmol} / \mathrm{L}$ for males, $\geq 1.2 \mathrm{mmol} / \mathrm{L}$ for females 


\section{Non-attendance at clinic appointments}

Median non-attendance rate was $27(0-50) \%$. More than one quarter of individuals $(27 \%)$ missed more than half of all appointments. Higher non-attendance rate was positively correlated with a higher HbAlc $(r=0.3, p=<0.001)$.

\section{Index of multiple deprivation (IMD)}

We used the English Index of Multiple Deprivation 2015 (IMD) for each participant's postcode from the Ministry of Housing, Communities and Local Government. (Available at: https://www.gov.uk/government/statistics/english-indic es-of-deprivation-2015). Manchester Diabetes Centre serves an area of high social deprivation. Half of the cohort was in lowest quartile of the English Index of Multiple Deprivation (IMD $\leq 8211$ ) and $79 \%$ were in the lower half of the distribution. Higher levels of deprivation were positively correlated with higher rates of non-attendance. $(r=0.15$, $p=0.04)$. However, there was no correlation between IMD and $\mathrm{HbA1c}$, BMI, total, LDL cholesterol, and systolic or diastolic blood pressure. There was an association of lower levels of HDL ( $r=0.21, p=0.002)$ in those with the higher levels of deprivation and a trend towards higher triglycerides $(r=0.14, p=0.06)$.

\section{Discussion}

In our study, only a small proportion of young adults achieved good glycaemic control. Non-attendance was high. Overweight and obesity were common with approximately half of the cohort having a BMI $>25 \mathrm{~kg} / \mathrm{m}^{2}$. Onethird had a TC $>5 \mathrm{mmol} / \mathrm{L}$ and one-fifth had LDL-cholesterol $>3 \mathrm{mmol} / \mathrm{L}$. A combination of poor glycaemia, obesity, and dyslipidaemia can contribute to avoidable microvascular and macrovascular complications and poor long-term health outcomes.

The UK National paediatric diabetes audit 2015/16 reported similar HbA1c levels in 20-24 years old: mean HbA1c; men: $69 \mathrm{mmol} / \mathrm{mol}$; women: $84 \mathrm{mmol} / \mathrm{mol}$ [3]. However, this report included only 26 individuals in that age range. Our study is considerably larger $(n=240)$ and, therefore, provides more precision in the estimate of glucose control. McKnight et al. published an international comparison of glycaemic control in T1DM in three age groups [4]. They reported a median $\mathrm{HbA} 1 \mathrm{c}$ of $76 \mathrm{mmol} / \mathrm{mol}(9.1 \%)$ in 15-24 years old in England and Wales $(n=20,939)$. The USA Type 1 diabetes exchange investigators also evaluated HbA1c data in 2867 individuals aged $18-25$ years [5]. Mean HbAlc was $8.7 \%$ compared to $9.0 \%$ this study.

Ours is the first study in the UK to report $\mathrm{HbAlc}$, cardiometabolic risk factors, and attendance in 18-25 years old specifically. Our findings may be generalizable to the other UK centers. Key limitation is the single-center retrospective nature of study. Other limitations include lack of information about rates of hypoglycaemia, hospital admissions due to diabetic ketoacidosis, and information about education provided to participants.

Our data highlight poor glycaemic control regardless of insulin delivery method, high rates of non-attendance, and other adverse cardio-metabolic risk factors among 18-25 years old with diabetes. There is an urgent need to further research the underlying reasons for these observations with a view to improve care and engagement with young adults who may benefit from new service delivery models.

Acknowledgements Current and previous staff at Manchester Diabetes Centre, Royal Manchester Children's Hospital, and Manchester University NHS Foundation Trust.

Author contributions FN \& LL had full access to all of the data in the study and takes responsibility for the integrity of the data. FN \& LL take responsibility for the accuracy of the data analysis. All authors codesigned the study. FN collected data. FN \& LL carried out the data and statistical analyses. All authors contributed to the interpretation of the results. FN, HT, LL and MR wrote the manuscript. All authors critically reviewed the report. No writing assistance was provided.

Funding This research did not receive any specific grant from funding agencies in the public, commercial, or not-for-profit sectors.

\section{Compliance with ethical standards}

Conflict of interest LL reports having received speaker honoraria from Animas, Abbott, Insulet, Medtronic, Novo Nordisk, Roche, and Sanofi. Advisory panel for Animas, Abbott, Novo Nordisk, and Roche. MKR has acted as a consultant for GSK, Roche, and MSD, and also participated in advisory board meetings on their behalf. MR has received lecture fees from MSD and grant support from Novo Nordisk, MSD, and GSK. FN, $\mathrm{AU}, \mathrm{MM}, \mathrm{ID}$, and HT declare no conflict of interests.

Ethical approval For this retrospective service evaluation study using routinely collected data, ethical approval in not requested.

Informed consent For this type of study formal consent is not required.

Open Access This article is distributed under the terms of the Creative Commons Attribution 4.0 International License (http://creativeco mmons.org/licenses/by/4.0/), which permits unrestricted use, distribution, and reproduction in any medium, provided you give appropriate credit to the original author(s) and the source, provide a link to the Creative Commons license, and indicate if changes were made.

\section{References}

1. Lyons SK, Becker DJ, Helgeson VS (2014) Transfer from pediatric to adult health care: effects on diabetes outcomes. Pediatr Diabetes 15(1):10-17 (Epub 2013/12/20)

2. The Diabetes Control and Complications Trial Research Group, Epidemiology of Diabetes Interventions Complications Research Group (2014) Effect of intensive diabetes therapy on the progression of diabetic retinopathy in patients with type 1 diabetes: 18 years 
of follow-up in the DCCT/EDIC. Diabetes. https://doi.org/10.2337/ db14-0930

3. Royal College Of Paediatrics and Child Health. National paediatric diabetes audit 2015-2016 Report 1: care processes and outcomes. 2015-2016. https://www.rcpch.ac.uk/resources/national-paediatric -diabetes-audit-npda-national-reports. Accessed 13 Dec 2018

4. McKnight JA, Wild SH, Lamb MJ et al (2015) Glycaemic control of Type 1 diabetes in clinical practice early in the 21 st century: an international comparison. Diabet Med 32(8):1036-1050 (Epub 2014/12/17)

5. Miller KM, Foster NC, Beck RW et al (2015) Current state of type 1 diabetes treatment in the US: updated data from the T1D exchange clinic registry. Diabetes Care 38(6):971-978 (Epub $2015 / 05 / 23)$ 